\title{
Descripción Anatómica, Histológica y Ultraestructural de la Branquia e Hígado de Tilapia (Oreochromis niloticus)
}

\author{
Anatomical, Histological and Ultraestructural Description \\ of the Gills and Liver of the Tilapia (Oreochromis niloticus)
}

"G. A. Torres R.; ** S. González P. \& *** E. Peña S.

\begin{abstract}
TORRES, R. G. A.; GONZÁLEZ, P. S. \& PEÑA, S. E. Descripción anatómica, histológica y ultraestructural de la branquia e hígado de tilapia (Oreochromis niloticus). Int. J. Morphol., 28(3):703-712, 2010.

RESUMEN: La tilapia (Oreochromis niloticus) es un pez presente en muchos ecosistemas de agua dulce, en diversas regiones de Colombia. Esta especie es una fuente de alimentación de alta demanda de la población en general, por lo cual es de gran interés que su hábitat acuícola esté libre de contaminantes, con el fin que el especimen se desarrolle y crezca normalmente y así pueda ser consumido por el ser humano sin ningún perjuicio. Las branquias y el hígado de peces son considerados como los órganos primarios donde detectar efectos de polución. Este estudio muestra la morfología normal de las branquias e hígado de tilapia, a través de microscopías: de luz, óptica de alta resolución (MOAR), electrónica de transmisión (TEM) y de barrido (MEB); como un estudio básico para futuras investigaciones, en las cuales se puedan comparar tejidos sanos y tejidos expuestos a contaminantes ambientales; por lo cual, este análisis podría ser utilizado como referente para la aplicación como biomarcador histopatológico de estrés ambiental. Para esta investigación se recolectaron especímenes en un afluente del Río Patía (Departamento del Cauca). Sacrificado el animal, se disecó el arco branquial izquierdo y el hígado. Las biopsias se fijaron con las técnicas estándares para microscopías de luz y electrónica. En los cortes obtenidos se observa la organización en forma detallada de los diferentes tejidos que componen a las branquias y al hígado de especímenes sanos.
\end{abstract}

PALABRAS CLAVE: Branquia; Hígado; Morfología; Cichlidae.

\section{INTRODUCCIÓN}

En esta investigación se describen como órganos de estudio, las branquias e hígado de Oreochromis niloticus. Las branquias son los órgano respiratorios en los peces, encargados de realizar el intercambio gaseoso, el conocimiento de su morfología y su fisiología es de gran importancia porque al describir sus características estructurales normales, aporta nociones valiosas para determinar lesiones y enfermedades causadas por diversos agentes contaminantes, ya que estos órganos junto con los riñones, el hígado y la piel, son considerados como órganos primarios u órganos blancos, útiles para evaluar el efecto de la polución (Bernet et al., 1999) y, por lo tanto, son importantes para ser utilizados en la aplicación como biomarcadores histopatológicos (Giari et al., 2007; Verján et al., 2001). Los daños morfológicos de los fila- mentos que forman parte de la estructura de las branquias, debido a la exposición a metales, sólidos suspendidos y otras sustancias tóxicas, interfieren con la alimentación, crecimiento y desarrollo del individuo; por lo que es considerado como un indicador de importancia ecológica usado frecuentemente (Viarengo et al., 2007; Verján et al.; Lyons et al., 2006).

El hígado en los peces realiza funciones tanto hepáticas como pancreáticas; es el órgano metabolizador por excelencia de todas las sustancias que le llegan por vía sanguínea, por lo cual, este órgano sirve como referente histológico para el análisis del daño tisular causado por sustancias contaminantes del medio ambiente como pesticidas, metales pesados y otros (Amaral et al., 2002).

\footnotetext{
Unidad de Miscrocopia Electrónica, Universidad del Cauca. Popayán. Colombia.

** Facultad Ciencias de la Salud. Departamento de Morfología. Universidad del Cauca. Popayán. Colombia.

*** Facultad de Ciencias Naturales y Exactas. Universidad del Valle. Cali. Colombia.

Proyecto financiado por Colciencias Código 1106-335-18552, Contrato RC NO 202- 2006.
} 


\section{MATERIAL Y MÉTODO}

Los adultos sanos de tilapia (Oreochromis niloticus) fueron colectados de un afluente del río Patía (Departamento del Cauca), ecosistema libre de contaminantes. Se registró el peso y longitud de los individuos, se anestesiaron con tricaine methane sulfonato (MS-222), se sacrificaron por punción medular (Verján et al.). Fueron disecados el segundo arco branquial izquierdo y el hígado, se tomaron biopsias de éstos y las muestras se procesaron para microscopíaa de luz (ML), óptica de alta resolución (MOAR), electrónica de barrido (MEB) y transmisión (MET). Para ML las muestras se fijaron en formol bufferado $3,7 \%$ y se deshidrataron en alcoholes a partir de $50 \%$, se aclararon con xilol y se incluyeron en parafina. Las muestras fueron cortadas entre 4-5 mm, con un micrótomo LKB. Los cortes se hidrataron y tiñeron con hematoxilina-eosina, otros con PAS-alcian blue. Para las muestras analizadas con MOAR y TEM, las biopsias se fijaron en glutaraldehido al $0,2 \mathrm{M}$ en buffer fosfato a pH 7,4, se postfijaron con tetróxido de osmio al $2 \%$ y deshidrataron en etanol con concentraciones ascendentes. A las muestras se les hizo preimbibición en resina y óxido de propileno hasta incluir en resina epóxica. Los bloques se cortaron con ultramicrótomo Ultracut Leica en grosor de $0,7 \mathrm{a} 1 \mathrm{~mm}$. Los cortes se tiñeron con azul de toluidina, se observaron en microscopio Nikon eclipse 80i con sistema de análisis de imágenes Leica. QWIN 505. Para MET se obtuvieron cortes entre 70 a 90 nanómetros, los que fueron contrastados con acetato de uranilo y citrato de plomo y observados con un microscopio JEOL JEM 1200EX. Las muestras para MEB se deshidrataron en alcoholes de concentración ascendentes hasta etanol absoluto, se llevaron a mezclas de alcohol-acetona hasta acetona pura y se expusieron a un secador de punto crítico y se cubrieron con oro. Las muestras se observaron con un microscopio electrónico de barrido JEOL JSM 5310 LV.

\section{RESULTADOS}

Las branquias son órganos que se encuentran en cámaras ubicadas simétricamente a ambos lados del cuerpo, detrás de la cabeza. La macro arquitectura de la branquia de tilapia se puede delimitar a dos regiones bien definidas: el arco branquial y los filamentos (Figs. 1, 6, 7). Del arco se originan dos hileras de filamentos (Fig. 7). El arco branquial es un armazón de tejido óseo, cubierto y protegido en su superficie interna por una membrana serosa, por donde discurren los vasos sanguíneos de mayor calibre, como la arteria aferente del arco (Aaf) la cual se ramifica en vasos, de mediano calibre que irrigan a los filamentos y de menor ca- libre (vasos nutricios) y avanzan hasta la punta de la lamela, llevando sangre para el intercambio gaseoso. El retorno de la sangre se hace por la arteria eferente del arco (Aef), la que drena vasos más pequeños provenientes de los filamentos (Fig. 2). Externamente al hueso, se adosa una lámina de cartílago hialino, que se evagina proyectándose hacia los filamentos. Contigua al cartílago, justo en la base del filamento, se ubica la túnica muscular que genera cierto grado de movimiento a los filamentos, creando turbulencia en el microambiente acuático, facilitando el intercambio de sustancias. Para cumplir con su función respiratoria, las branquias presentan una combinación de especializaciones cuya función principal es aumentar la superficie de área relativa, aumentando la eficacia para el intercambio gaseoso. Los filamentos son especializaciones constituidos por un núcleo de cartílago hialino que les brinda soporte y les da la forma característica. Sobre la superficie del cartílago se adosa la mucosa del filamento, la cual está formada por epitelio plano simple y una lámina propia de tejido conectivo laxo. La evaginación del epitelio del filamento es otra especialización para aumentar área de superficie. Las lamelas (Figs. 3 y 8) son estructuras digitiforme, cubiertas por un epitelio plano simple (epitelio lamelar), el cual forma pliegues cuyo análisis ultraestructural muestra una organización a manera de huellas dactilares (Fig.10) aumentando la superficie de intercambio; además, las células epiteliales planas facilitan el intercambio rápido del el $\mathrm{O}_{2} \mathrm{y} \mathrm{CO}_{2}$. Entremezcladas con las células planas, se ubican varias poblaciones celulares, tales como las células pilares que regulan el flujo sanguíneo de los canales pilares (Fig. 11), son macrófagos y forman parte del sistema retículo endotelial, fagocitan partículas extrañas, patógenos, especialmente bacterias, ya que producen lisozima y son células presentadoras de antígenos; constituyendo la primera línea de defensa de las branquias (Ferguson, 2006).

Otra población celular presente, es la de células caliciformes secretoras de mucina, la cual forma una película de protección mecánica para el epitelio, creando una interfase entre el ambiente acuoso y el tejido, además, participan en la regulación iónica y protección inmunológica, actuando como barrera contra agentes patógenos y sustancias toxicas (Ferguson, 2006) (Figs. 4 y 9). Especialmente en la base de la lamela y en el epitelio opercular, se encuentran la célula osmorreguladora de cloro, rica en mitocondrias, secreta $\mathrm{NaCl}$ a través de un gradiente electroquímico producido por la acción de una ATPasa $\mathrm{Na}+/ \mathrm{K}+$, (Figs. 5 y 12), participando en el balance ácido base y procesos de aclimatación (Biagini et al., 2009; Daborn et al., 2001). El epitelio lamelar se dispone de tal manera que en el centro de ésta se forma el canal pilar por donde discurre un vaso tipo capilar por el cual circulan eritrocitos que avanzan hasta la punta de la lamela (Fig. 11). El capilar de la lamela está 
formado por un endotelio (epitelio plano simple) y su lámina basal, el cual, junto con el epitelio lamelar (plano simple y su lámina basal) forman una barrera hemodinámica, exponiendo a los eritrocitos muy cerca del medio acuático para realizar el intercambio de gases; confiriendo las propiedades de órgano respiratorio a las branquias (Figs. 4, 5 y 11). La posición y la distancia entre lamela y lamela en el filamento mantiene una simetría, al igual que el espesor de los
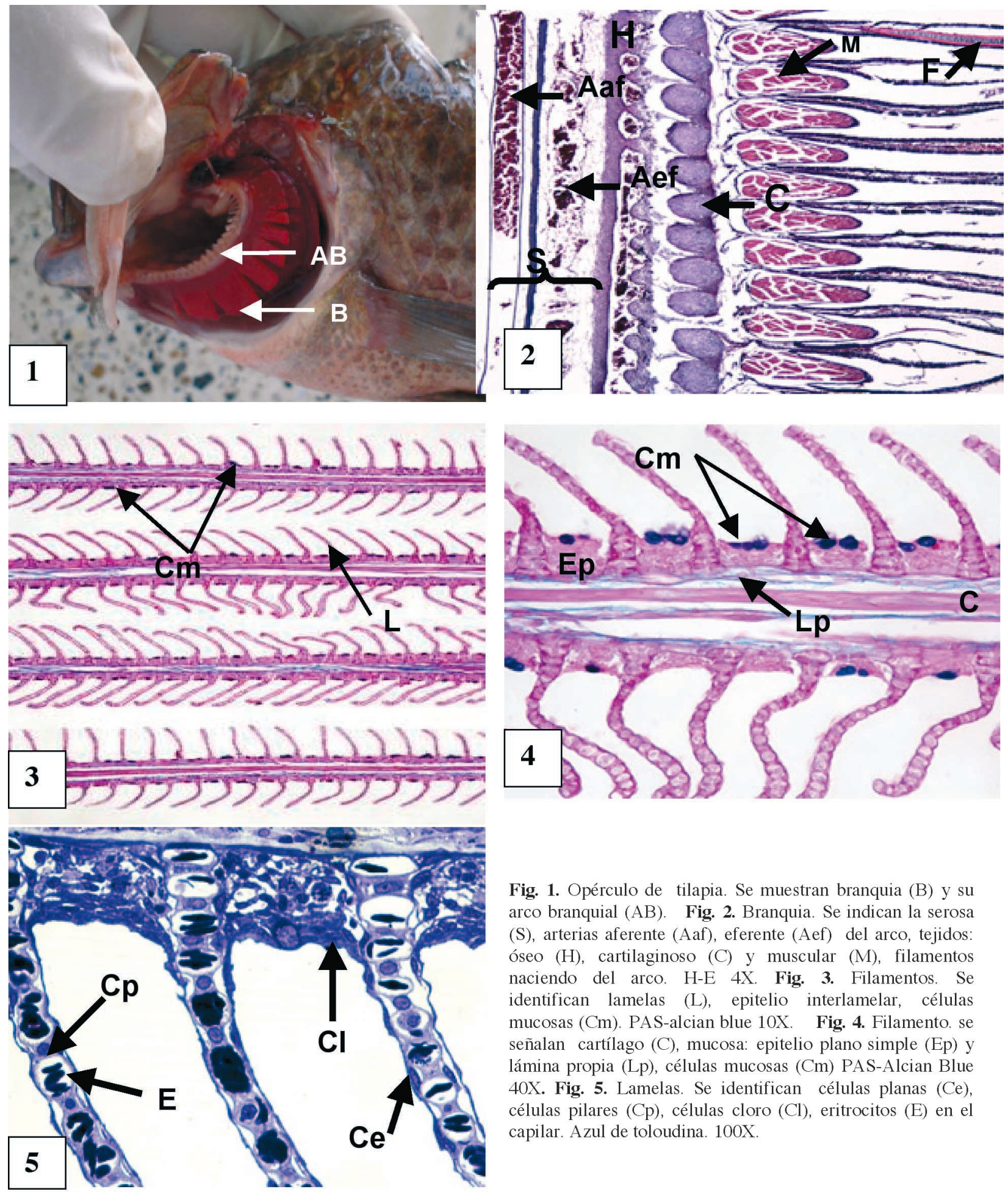

Fig. 1. Opérculo de tilapia. Se muestran branquia (B) y su arco branquial (AB). Fig. 2. Branquia. Se indican la serosa (S), arterias aferente (Aaf), eferente (Aef) del arco, tejidos: óseo $(\mathrm{H})$, cartilaginoso (C) y muscular (M), filamentos naciendo del arco. H-E 4X. Fig. 3. Filamentos. Se identifican lamelas (L), epitelio interlamelar, células mucosas $(\mathrm{Cm})$. PAS-alcian blue 10X. Fig. 4. Filamento. se señalan cartílago (C), mucosa: epitelio plano simple (Ep) y lámina propia $(\mathrm{Lp})$, células mucosas $(\mathrm{Cm}) \mathrm{PAS}-\mathrm{Alcian}$ Blue 40X. Fig. 5. Lamelas. Se identifican células planas (Ce), células pilares $(\mathrm{Cp})$, células cloro $(\mathrm{Cl})$, eritrocitos $(\mathrm{E})$ en el capilar. Azul de toloudina. 100X 


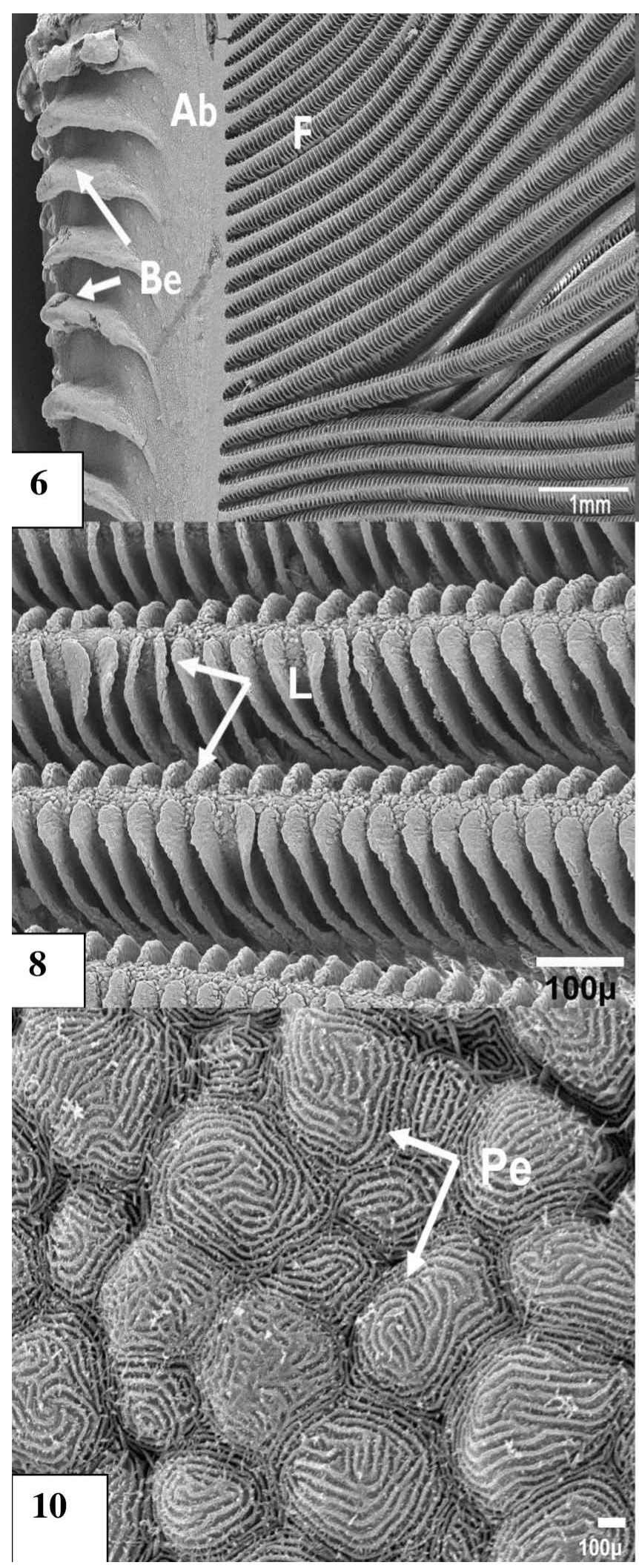

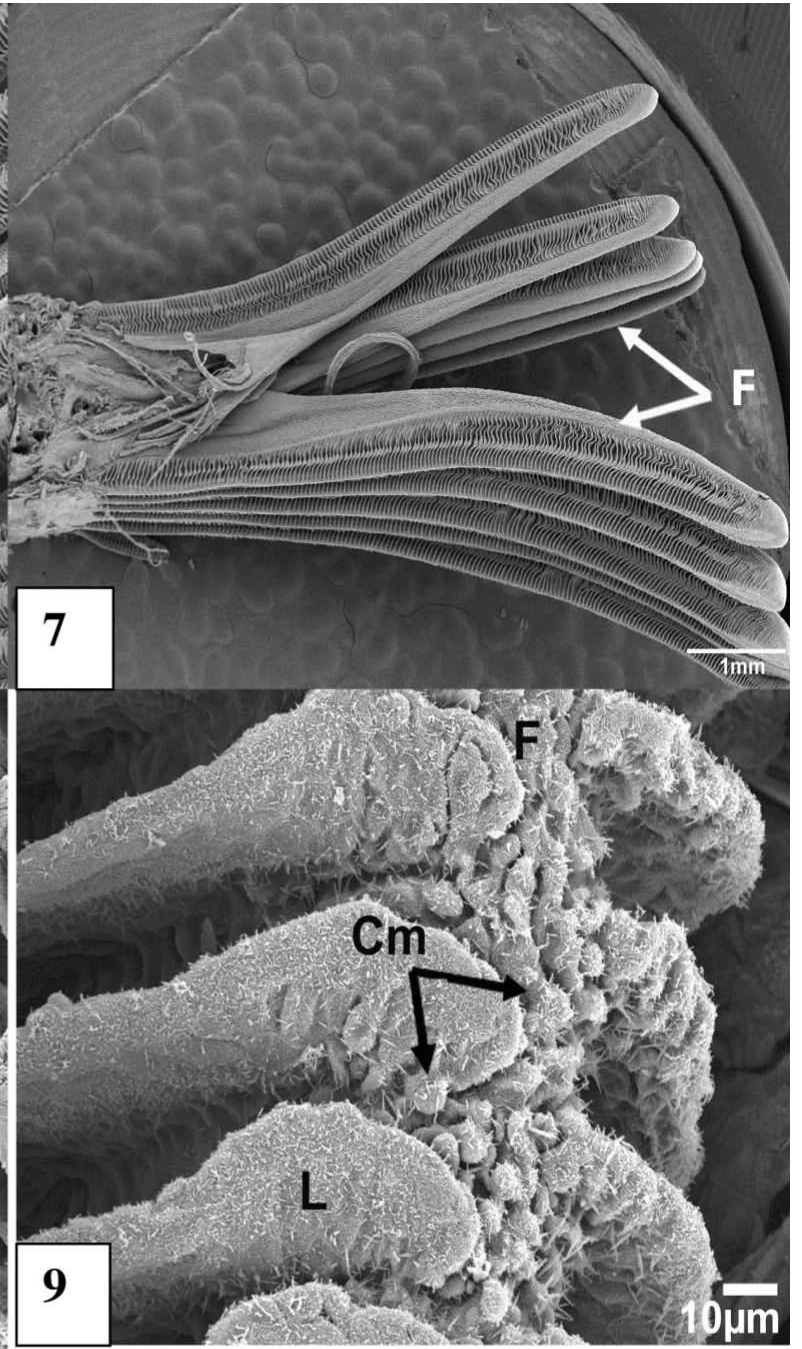

Micrografías electrónicas de barrido. Branquia de tilapia.

Fig. 6. Se indican soporte óseo del arco branquial (Ab), branquiospinas (Be). Nótese el nacimiento de filamentos (F) del arco branquial. Fig. 7. Se muestran las dos hileras de filamentos (F). Fig. 8. En los filamentos es possible apreciar la disposición y simetría de las lamelas (L). Fig. 9. Se presentan células mucosas $(\mathrm{Cm})$ en las superficies del filamento (F) y lamelas (L). Fig. 10. Se muestra el epitelio lamelar formando pliegues epiteliales (Pe) semejantes a huellas dactilares. 


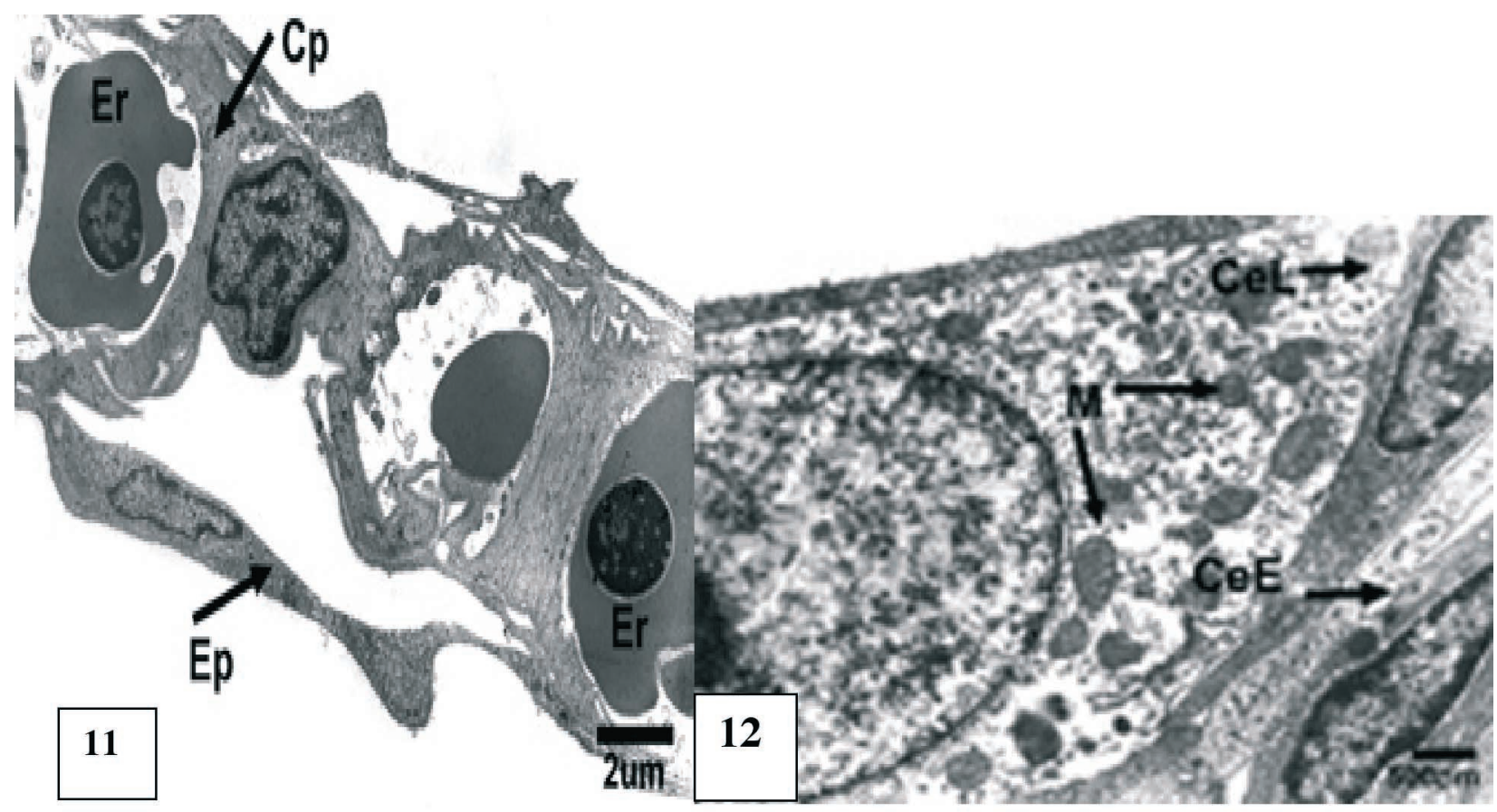

Fig. 11. Micrografía TEM de lamela, Se señalan: un célula plana (Ep) del epitelio lamelar, células pilar (Cp), eritrocitos (Er) en el capilar. Fig. 12. Célula de cloro. Se reconoce por la abundancia de mitocondrias (M). Cerca de la célula se identifican: célula plana del epitelio lamelar $(\mathrm{CeL})$ y célula plana $(\mathrm{CeE})$ del endotelio capilar; formando una bicapa celular que constituye una barrera hemodinámica para el intercambio gaseoso que realiza la lamela.

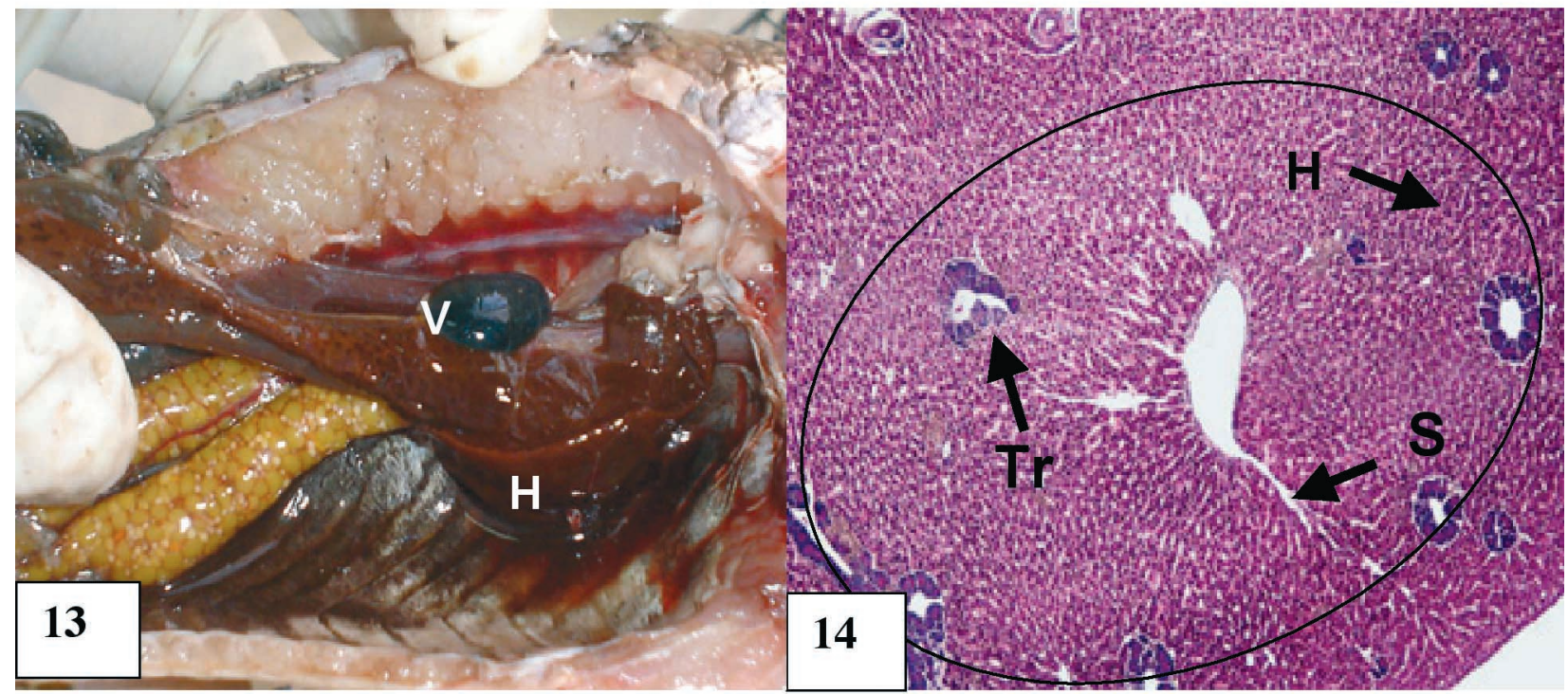

Fig. 13. Vista macroscópica de hígado de tilapia. Se presentan sus lóbulos y l a vesícula biliar. Fig. 14. Componente hepático: Lobulillo hepático clásico (círculo), tríadas (Tr), vena central (Vc), cordones de hepatocitos. (H) y sinusoides (S). $\mathrm{H}-\mathrm{E}, 10 \mathrm{X}$. 


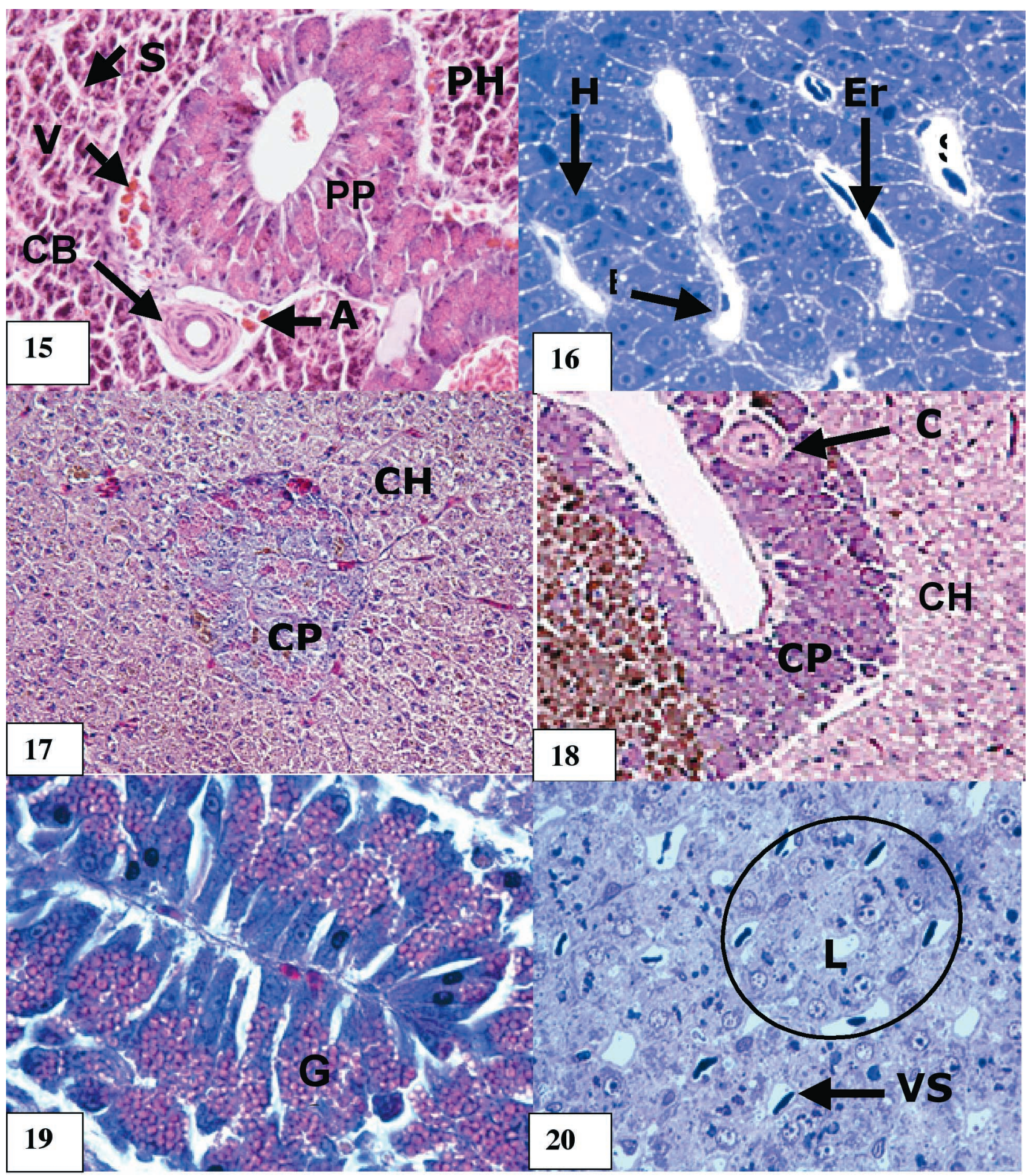

Fig. 15. Hígado. Triada $\mathrm{c}$ on arteria (A); Conducto biliar (CB) y vena (V). Se indican los hepatocitos (PH), sinusoides (S) y acúmulo pancreático (PP) H-E. 40X. Fig. 16. Componente hepático. Hepatocitos (H), endotelio (E) del sinusoide (S) con eritrocitos (Er) Azul de toluidina. 100X. Fig. 17. Se muestra acúmulo celular del componente pancreático (CP) y componente hepático (CP). H-E.10X. Fig. 18. Se muestran componente hepático $(\mathrm{CH})$ y pancreático (CP) y un conducto (C). H-E.10X. Fig. 19. Acúmulo de células serosas con gránulos de cimógeno $(G)$ en región pancreática. H-E. 100X. Fig. 20. Acino pancreático con su luz (L) su núcleo redondo, basal y nucléolo y vasos sanguíneos (VS) en el tejido. Azul de toluidina.100X. 
epitelios fenómeno de importancia crítica, ya que cuando son afectados limita la eficiencia de intercambio de gases; alterando la simetría lamelar; perturbando, por lo tanto, lo que se conoce como Distancia de Difusión Efectiva (DDE) y produciendo la disfunción del órgano (Ferguson; Sanchez et al., 1997).

El hígado en los peces realiza funciones que los mamíferos hacen por separado con el hígado y el páncreas. En la tilapia el hígado se localiza en la región media y anterior de la cavidad abdominal, se divide en lóbulos que se relacionan con el intestino a lo largo de la cavidad (Fig. 13). Esta glándula está constituida por un estroma y parénquima. El estroma corresponde al tejido de sostén, como la cápsula que recubre, protege e individualiza al órgano. Desde la cápsula parten tabiques hacia el interior, en el cual se encuentra un retículo de tejido conectivo laxo que sostiene al parénquima. El parénquima está representado por dos componentes anatómicos: el hepático y el pancreático. El componente hepático corresponde a una glándula mixta compuesta por los hepatocitos (función endocrina) y a un sistema de conductos que drena la bilis (función exocrina). Los hepatocitos son células poliédricas, grandes con un núcleo redondo con un nucléolo característico. Estas células forman cordones o acúmulos organizados al lado del sinusoide constituido por endotelio y lámina basal. Asociados a la estructura del sinusoide se encuentran macrófagos (células de Kupfer) pertenecientes al sistema retículo endotelial y constituyen la primera línea de defensa del hígado (Fig. 14). La membrana celular del hepatocito, en sus superficies laterales se evagina formando microvellosidades que se proyectan hacia un espacio ubicado entre el hepatocito y el sinusoide, denominado espacio perisinuidal (de Disse) (Figs. 22 y 22), en el cual son absorvidas, moléculas que difunden desde el plasma sanguíneo del sinusoide, cuyo flujo proviene de la vena portal y de la arteria hepática. Asímismo las sustancias metabolizadas por el hepatocito difunden hacia el espacio de Disse y de éste hacia el sinusoide, drenado por la vena central, la cual se ubica en el centro de cada lobulillo; éstas se anastomosan formando la vena hepática que lleva la sangre a la circulación general. La organización de estos componentes forman un área especializada: el lobulillo hepático, unidad estructural y funcional del hígado. Cada lobulillo, de tamaño y forma variables está constituido por las triadas hepáticas, formadas por una rama de la vena portal (rica en nutrientes del intestino delgado), una rama de la arteria hepática (rica en $\mathrm{O}_{2}$ y nutrientes) y un conducto biliar; compuesto por epitelio cúbico simple, el cual es formado por la unión de varios canalículos biliares; estructuras originadas por la fusión de las membranas apicales de hepatocitos vecinos de un mismo cordón. El canalículo es la estructura que drena la bilis de los hepatocitos. Los conductos biliares confluyen, formando un conducto de mayor calibre que se dirige hacia el intestino delgado, en donde vierte la bilis para emulsificar las grasas. Las estructuras que componen las triadas se unen por tejido conectivo y se organizan estratégicamente para delimitar al lobulillo. (Figs. 14, 15 y 16). Entremezclados con el parénquima hepático se distribuyen acinos o masas de células serosas que constituyen el parénquima del páncreas. Estas células serosas son de forma piramidal con un núcleo redondo, un nucléolo prominente, su citoplasma contienen gránulos con abundantes proenzimas digestivas (cimógenos) que se activan en la luz intestinal (Figs. 17, $18,19,19,20$ y 23). Estas sustancias son secretadas por exocitosis en su membrana apical hacia un vaso sanguíneo presente en todo el centro de la luz acinar; en ella se visualiza el endotelio vascular.

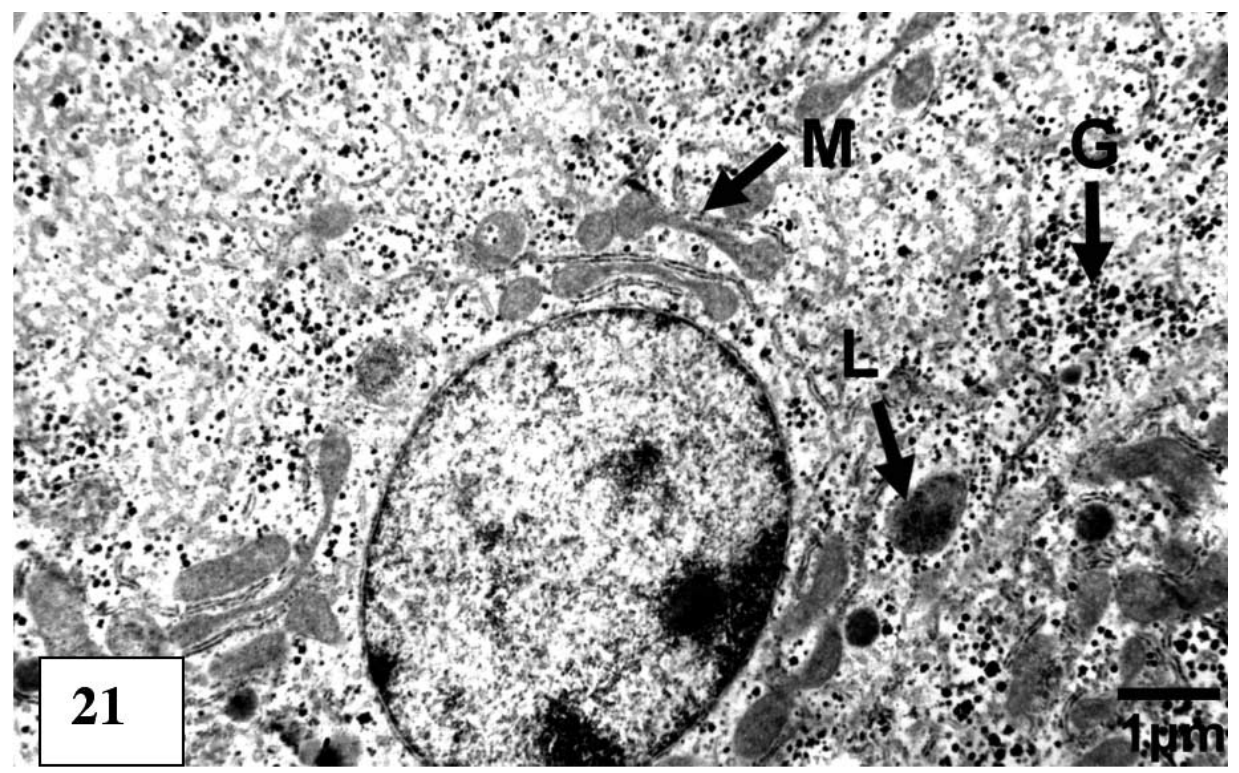

Fig. 21. Micrografía TEM de hígado. En el componente hepático se observa un hepatocito el cual se caracteriza por su gran cantidad de mitocondrias (M) con su forma característica, son identificables gránulos de glucógeno (G) y algunos lisosomas (L). 


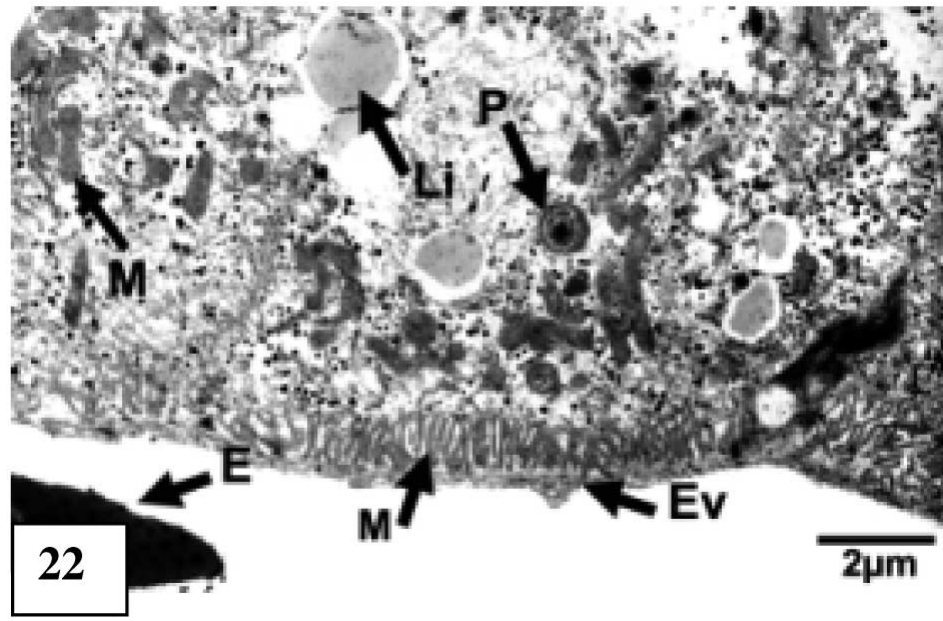

Fig. 22. Micrografía TEM de hígado. En el componente hepático se identifica un hepatocito en cuyo citoplasma son observables mitocondrias (M), peroxisomas $(\mathrm{P})$ e inclusiones lipídicas (Li). En su superficie lateral se identifican microvellosidades $(\mathrm{M})$ en el espacio perisinuidal. Se prsenta el endotelio (Ev) del sinusoide y en su luz un eritrocito (E).

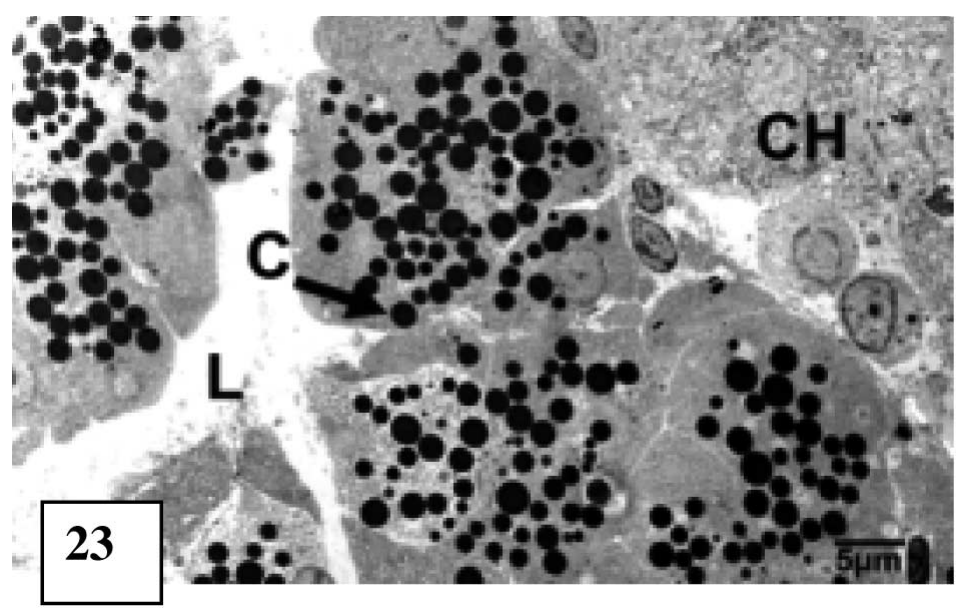

Fig. 23. Micrografía TEM de hígado. En el componente pancreático se observan células de forma piramidal cuyo citoplasma se caracteriza por la abundancia de gránulos de cimógeno (C). Los ápices de las células convergen en la luz (L). En el lado derecho se indica el componente hepático $(\mathrm{CH})$.

\section{DISCUSIÓN}

El detrimento ambiental de las fuentes hídricas causa daños y un deterioro en la salud de los organismos expuestos a los contaminantes, principalmente especies de peces como la tilapia, de uso en la dieta humana. Consideramos que todos los esfuerzos en la investigación básica para el conocimiento de los tejidos normales en esta especie, permitirá determinar los daños causados y sus efectos por la contaminación de ambientes acuáticos, por lo cual la conservación de este medio, debe despertar gran interés y ser promovido por instituciones encargadas del manejo ambiental.
La branquia es el principal órgano blanco por contaminantes (Biagini et al.); su tejido epitelial es un excelente parámetro para evaluar los efectos de variables ambientales, sustancias tóxicas y calidad del agua (Verján et al.; Mazon et al., 2002; Wong \& Wong, 2000).

La descripción histológica como la ultraestructural de la branquia muestra la complejidad de sus tejidos y entre ellos, el epitelial cuya estructura permite el intercambio óptimo de gases y de otras sustancias. La formación de los pliegues en la mucosa y la morfología de micropliegues, con su capa de glicocálix, son consideradas estructuras importantes en la retención de moco y son extremadamente sensible al estrés, grado de madures celular y cambios ambientales (Mazon et al.; Wong \& Wong; Ferguson). Por otra parte, las branquias han sido evaluadas como indicadores de la presencia de sustancias tóxicas, como metales, entre otras. Las lesiones tisulares observadas en las branquias de los peces constituye una metodología reconocida y rápida para determinar los daños (Ferguson et al., 1992; Sánchez et al.). El aneurisma, la fusión lamelar, la hiperplasia del epitelio, entre otras, son alteraciones conducentes a trastornos funcionales de las branquias y son utilizadas hoy en día como biomarcadores histopatológicos para estudios de evaluación ambiental (Verján et al.; Cengiz, 2006).

Daborn et al. estudiaron la estructura y función de las células de cloro; reportando variaciones en su morfología por cambios dados en la salinidad, acidificación, e hiperoxia; además, los autores consideran que estas células participan en procesos de aclimatación por salinidad, en respuesta a un simple estimulo osmótico, demostrando las potencialidades en estudios electrofisiológicos y de evaluación ambiental.

La estructura histológica del hígado de Oreocrhomis niloticus muestra hepatocitos alineaos en filas conformando cordones de forma muy similar en muchos teleóstos. Identificamos los lobulillos hepáticos, y las triadas, por lo cual discrepamos en las observaciones realizadas por Vicentini et al. (2005); sin embargo, coincidimos en la observación acinos pancreáticos asociados a ductos biliares localizados dentro del parénquima hepático identificados también por otros autores (Ferguson). Ultraestructuralmente, los hepatocitos presentan características muy similares, como el alto conteni- 
do de glucógeno en su citoplasma y relativamente pobre en organelas como lo reportado por Vicentini et al.

La histopatología hepática como biomarcador tiene una amplia aplicación, la presencia de lesiones inflamatorias, toxicohepáticas, preneoplásicas, y neoplásicas, se han convertido en una valiosa herramienta integrativa en programas de monitoreo ambiental (Lyons; Schmalz et al., 2002; Amaral et al.). Los resultados mostrados en este trabajo apoyan la aplicación en el conocimiento de un espécimen saludable de gran interés en la dieta humana, así como en la aplicación como biomarcador histopatológico constituyen un complemento de las metodologías tradicionales en estudios de evaluación de contaminación y riesgo ambiental.

AGRADECIMIENTOS. Los autores agradecen el apoyo y financiamiento a colciencias; con el Proyecto Código 1106-335-18552 contrato RC NO 202- 2006 realizado por las Universidades del Cauca y Valle del Cauca, Colombia, el cual permitió realizar esta investigación.

TORRES, R. G. A.; GONZÁLEZ, P. S. \& PEÑA, S. E. Anatomical, histological and ultraestructural description of the gills and liver in Tilapia(Oreochromis niloticus) Int. J. Morphol., 28(3):703-712, 2010.

SUMMARY: The tilapia (Oreochromis niloticus) is a fish that can be found in many of the sweet water ecosystems throughout various regions of Colombia. This species is a high demand food source for the population in general and therefore it is important that its aquaculture habitat remains free of contaminating pollutants, in order that the species develop and grow normally for adequate human consumption. The branchia and the liver of fish are considered the primary organs wherein the effects of pollution can be detected. This study shows the normal morphology of the branquia and the liver of the tilapia through light microscopy, high resolution optical microscopy, electronic transmission microscopy, and electronic scanning microscopy, as basic research for future investigation in which healthy tissue and tissue exposed to environmental pollutants can be compared. This analysis is thus used as reference for the application as a histopathological marker of environmental stress. For purposes of this research specimens of a tributary of the Patia river (Departamento de Cauca) were collected. The animal was sacrificed, the left branquial arch and the liver were dissected; the biopsies were set for standard light microscopy as well as electronic microscopy. The organization is shown in detail in the slices obtained in the different tissue which compose the branquia and the liver of healthy specimen.

KEY WORDS: Gills; Liver; Morphology; Cichlidae.

\section{REFERENCIAS BIBLIOGRÁFICAS}

Amaral, A. F.; Alvarado, N.; Marigomez, I.; Cunha, R.; Hylland, K. \& Soto, M. Autometallography and metallothionein immunohistochemistry in hepatocytes of turbot (Scophthalmus maximus L.) after exposure to cadmium and depuration treatment. Biomarkers, 7:491500,2002

Bernet, D.; Schmidt, H.; Meier, W.; Bukhardt-Holm, P. \& Wahli, T. Histopathology in fish: Proposal for a protocol to assess aquatic pollution. J. Fish Dis., 22:25-34, 1999.

Biagini, F. R.; de Oliveira, J. A. \& Fontanetti,, C. S. The use of histological, histochemical and ultramorphological techniques to detect gill alterations in Oreochromis niloticus reared in treated polluted waters. Micron., 40:839-44, 2009.

Cengiz, E. I. Gill and kidney histopathology in the freshwater fish Cyprinus carpio after acute exposure to deltamethrin. Environ. Toxicol. Pharmacol., 22:200-4, 2006.
Daborn, K.; Cozzi, R. R. F. \& Marshall, W. S. Dynamics of pavement cell-chloride cel interactions during abrupt salinity change in Fundulus heteroclitus. J. Exp. Biol., 204:1889-99. 2001.

Ferguson, H. Systemic Pathology of Fish: A Text and Atlas of Normal Tissues in Teleosts and their Responses in Disease. $2^{\text {nd }}$ Ed. London, Scotian Press, 2006.

Ferguson, H. W.; Morrison, D.; Ostland, V. E.; Lumsden, J. \& Byrne, P. Responses of mucus-producing cell gill disease of rainbow trout (Oncorhychus mykiss). J. Comp. Path., 106:255-65, 1992.

Giari, L.; Manera, M.; Simoni, E. \& Dezfuli, B. S. Cellular alterations in different organs of European sea bass Dicentrarchus labrax (L.) exposed to cadmium. Chemosphere, 67:1171-81, 2007.

Lyons, B. P.; Stentiford, G. D.; Bignell, J.; Goodsir, F.; Sivyer, D. B.; Devlin, M.; Lowe, D.; Beesley, A.; Pascoe, C. K..; Moore, M. N. \& Garnacho, E. A biological effects 
TORRES, R. G. A.; GONZÁLEZ, P. S. \& PEÑA, S. E. Descripción anatómica, histológica y ultraestructural de la branquia e hígado de tilapia (Oreochromis niloticus). Int. J. Morphol, 28(3):703-712, 2010.

monitoring survey of Cardigan Bay using flatfish histopathology, cellular biomarkers and sediment bioassays: Findings of the Prince Madog Prize 2003. Environ. Res., 62:S342-6, 2006

Mazon, A. F.; Cerqueira, C. C. C. \& Fernandes, M. N. Gill cellular changes induced by cooper exposure in the South American tropical fishwater fish Prochilodus scrofa. Environ. Res., 88:52-63, 2002.

Sanchez, J. G.; Speare, D. J. \& Johnson, G. J. Morphometric and histochemical assessment of the branchial tissue response of rainbow trout, Oncorhynchus mykiss (Walbaum), associated with chloramines-T treatment. $J$. Fish Dis., 20:375-81, 1997.

Schmalz, W. F. Jr.; Hernandez, A. D. \& Weis, P. Hepatic histopathology in two populations of the mimmichog, Fundulus heteroclitus. Mar. Environ. Res., 54:539-42, 2002.

Verján, N.; Iregui, C. A.; Rey, A. L. \& Donado, P. Sistematización y caracterización de las lesiones branquiales de la cachama blanca (Piaractus brachypomus) de cultivo clínicamente sana: algunas interacciones hospedador-patógeno-ambiente. AQUATIC: Revista Electrónica de Acuicultura. Tecnología e Investigación en Castellano, 15:1-25, 2001.

Viarengo, A.; Lowe, D.; Bolognesi, C.; Fabbri, E. \& Koehler, A. The use of biomarkers in biomonitoring: A 2-tier approach assessing the level of pollutant- induced stress syndrome in sentinel organisms. Comp. Biochem. Physiol. C Toxicol. Pharmacol., 146:281-300, 2007.

Vicentini, C. A.; Franceschini-Vicentini, I. B.; Bombonato, M. T. S.; Bertolucci, B.; Lima, S. G. \& Santos, A. S. Morphological study of the liver in the teleost Oreochromis niloticus. Int. J. Morphol., 23(3):211-6, 2005.

Wong, K. C. \& Wong, M. H. Morphological and biochemical changes in the gills of tilapia (Oreochromis mossambicus) to ambient cadmium exposure. Aquat. Toxicol., 48:517-27, 2000.
Dirección para correspondencia: Gerardo Andrés Torres R. Unidad de Miscrocopía Electrónica Universidad del Cauca Popayán COLOMBIA

Email: gantorres@gmail.com

Recibido : 19-05-2010

Aceptado: 22-06-2010 